\title{
Elastic moduli and elastic anisotropy of cold sprayed metallic coatings
}

\author{
Hanuš Seiner ${ }^{\mathrm{a}}$, Jan Cizek ${ }^{\mathrm{b}, 1}$, Petr Sedlák ${ }^{\mathrm{a}}$, Renzhong Huang ${ }^{\mathrm{c}}$, Jan Cupera ${ }^{\mathrm{b}}$, Ivo Dlouhy ${ }^{\mathrm{b}}$, \\ Michal Landa ${ }^{\mathrm{a}}$ \\ ${ }^{a}$ Institute of Thermomechanics, Academy of Sciences of the Czech Republic, Dolejškova 5, 18200 \\ Prague, Czech Republic \\ ${ }^{b}$ Netme Centre, Institute of Materials Science and Engineering, Brno University of Technology, \\ Technicka 2896/2, 61669 Brno, Czech Republic \\ ${ }^{c}$ Plasma Giken, 4-1 Imaichi, Yoriimachi, Osato-gun, Saitama 369-1214, Japan
}

\begin{abstract}
Resonant ultrasound spectroscopy is applied to analyze the elastic anisotropy of thick copper, aluminum, titanium, and nickel coatings prepared by cold spraying and to determine the respective elastic moduli. The results show that the coatings exhibit only weak deviations from perfect isotropy, and the obtained elastic moduli are comparable with those of the corresponding polycrystalline bulks. The increased internal friction observed in some of the studied coatings may indicate grain refinement and consequent grain boundary sliding.

Keywords: Kinetic spray; CGDS; Elastic properties; Metals and alloys; Deposition; Resonant Ultrasound Spectroscopy.
\end{abstract}

(C) 2013. This manuscript version is made available under the CC-BY-NC-ND 4.0 license (http://creativecommons.org/licenses/by-nc-nd/4.0/)

doi:10.1016/j.surfcoat.2016.02.057

Final version available from

http://www.sciencedirect.com/science/article/pii/S0257897216301165

\section{Introduction}

Cold spraying (CS, $[1,2,3,4,5,6,7])$ is a versatile and efficient method for deposition of relatively thick metallic coatings. Unlike the conventional thermal spraying methods

\footnotetext{
${ }^{*}$ Corresponding author, cizek@fme.vutbr.cz
} 
such as plasma spraying $[8,9,10]$, the CS process does not involve substantial heating or melting of the sprayed powders. Instead, the formation of the coating arises from a severe plastic deformation of the accelerated powder particles upon their impingement at the substrate $[11,12]$. Thereby, the oxidation or phase changes in the feedstock material are effectively reduced, as well as e.g. the magnitude of the secondary residual stresses arising from the thermal expansion mismatch [13]. As such, CS has recently received a lot of attention as a novel method applicable for sensitive metals and alloys that readily undergo chemical or structural changes at elevated temperatures. Among the sprayed metallic coatings, those prepared by CS frequently exhibit superior mechanical and physical properties [1, 7], such as Young's modulus [14], hardness [15], or electrical conductivity [16], often comparable to those of the respective bulks. Further to that, the coatings deposited via high-temperature processes generally exhibit high levels of anisotropy [4], a property arising due to their heterogeneous lamellar or splat-like microstructure $[4,17,18,19]$ and commonly regarded as undesired. In this paper, we show that the CS coatings do not exhibit any significant elastic anisotropy, as opposed to its high-temperature counterparts.

Resonant ultrasound spectroscopy (RUS, [20, 21, 22]) has been recently used to investigate elastic anisotropy of nickel coatings prepared by the high-velocity oxygen fuel (HVOF) and atmospheric plasma spraying (APS) methods [19] and of steel coatings [23] prepared by water-stabilized plasma (WSP) spraying. In all reported cases, the difference between the in-plane and out-of plane properties of the coatings were significant, with the values of the ratio $\alpha=E_{\mathrm{OOP}} / E_{\mathrm{IP}}$ between the out-of-plane Young's modulus $\left(E_{\mathrm{OOP}}\right)$ and the in-plane Young's modulus $\left(E_{\mathrm{IP}}\right)$ ranging from 0.36 (for APS [19]) to 0.87 (for WSP [23]). Here we apply this method to determine the elastic constants and the strength of anisotropy for pure copper, aluminum, titanium and nickel coatings prepared by CS. The main advantage of the RUS method is that it enables the determination of all independent elastic constants of an anisotropic solid from measurements of one small sample. In addition, the RUS enables also a direct assessment of the internal friction parameter of the examined material $Q^{-1}[21]$, which may bring an additional information on the integrity of the sprayed material or on density and activity of defects in it [24]. 


\section{Experimental Setup}

\subsection{Examined Materials}

Four commercially available powders were selected for the experiment: $\mathrm{Al}, \mathrm{Cu}, \mathrm{Ni}$, and Ti. Considering the aim of the study, i.e. evaluation of (an)isotropy of the cold spray technology as a method, the selection of the powders was made with the aim of having feedstock material of dissimilar properties. The powder particles (Fig. 1) differed in their apparent density (varying from 2.67-8.96 $\mathrm{g} \cdot \mathrm{cm}^{-3}$ ), morphologies (oval, fully spherical, angular; a consequence of different fabrication technologies), and average particle diameters $(21-40 \mu \mathrm{m})$.

\subsection{Coatings deposition}

The analyzed materials were then deposited via high-pressure cold spray system (PCS1000, Plasma Giken, Ltd., Japan) onto polycrystalline 6061 aluminum alloy substrates of commercial purity. The surface of the substrates was not grit-blasted prior to coatings deposition. However, chemical degreasing was used to remove any oil or contaminant films. The lateral dimensions of the coated areas were $150 \times 50 \mathrm{~mm}$ and the robot arm movement and number of passes were set to reach a total coating thickness of at least $10 \mathrm{~mm}$; the excessive thickness allowed subsequent cutting of the required samples. Further to that, the successive gun passes resulted in a further compaction of the underlying deposited layers, thereby lowering the inherent coating porosity. The spray parameters used in the deposition are proprietary to Plasma Giken and are not to be disclosed in the paper.

The properties of the fabricated coatings were studied using FE-SEM equipped with EDX mapping and EBSD detectors (Zeiss Ultra Plus) and XRD (X'Pert Pro X-ray diffractometer, Co- $\mathrm{K}_{\alpha}$ source, $\mathrm{K}_{\beta}$ absorption filter, $\mathrm{X}^{\prime}$ Celerator detector; PANalytical B.V.). To determine oxygen content in the materials, Leco TC 600 thermoevolution analyzer was employed. Image analysis and the Archimedes methods were used to calculate the internal coatings porosity and Vickers microhardness was measured at $1 \mathrm{kgf}$ load. 


\subsection{Resonant ultrasound spectrocopy}

From each of the sprayed materials, a small sample of a rectangular parallelepipedshape (approximately $3.5 \times 2.5 \times 1.5 \mathrm{~mm}^{3}$ ) was cut from the region close to the center of the sprayed area. Taking advantage of the layers compaction via impingement of particles from successive gun passes, the samples were cut from areas close to the substrate-coating interface. All samples were oriented so that longest and the shortest edge of the sample were always perpendicular to the spraying direction and aligned with the directions of motion of the nozzle during spraying. However, it was assumed (as usual for the sprayed materials $[19,23,25,26])$ that all samples exhibit transversal isotropy, i.e. that all directions perpendicular to the spraying direction are equivalent, and the elasticity of the material can be fully described by five independent elastic coefficients. In the shorten Voigt's notation, these elastic constants are $c_{11}, c_{12}, c_{13}, c_{33}$ and $c_{44}$, assuming that the spraying direction is aligned with $x_{3}$. The engineering constants $E_{\mathrm{IP}}$ and $E_{\mathrm{OOP}}$ introduced in the Introduction can be then recalculated from $c_{i j}$ by simple algebraic relations (see e.g. [27]).

For each sample, a resonant spectrum of free elastic vibrations was obtained in the frequency range 0.1-2 MHz, using a contact-less, laser-based RUS setup [22]. The vibrations were excited by short ( $8 \mathrm{~ns}$ ) infrared pulses from a Nd:YAG laser with nominal wavelength $1.064 \mu \mathrm{m}$ and pulse energy $25 \mathrm{~mJ}$ (Quantel ULTRA, USA) and recorded by a scanning laser vibrometer (24 MHz frequency bandwidth) incorporated in a Polytec Micro-System Analyzer MSA-500, which enabled an identification of the modal shapes corresponding to individual resonant peaks. The experiments were performed at ambient temperature $(295 \mathrm{~K}$, temperature control $\pm 0.05 \mathrm{~K})$ under a low pressure $(10 \mathrm{mbar})$ nitrogen atmosphere.

The resonant spectra were complemented by pulse-echo measurements of phase velocity of longitudinal waves in directions perpendicular to the individual faces of the samples [27], i.e. in the in-plane $\left(v_{\mathrm{IP}}\right)$ and out-of-plane $\left(v_{\mathrm{OOP}}\right)$ directions. The schematics of the RUS method applied within this study is shown in Fig. 2. 


\section{Results and discussion}

\subsection{Coating properties}

The fabricated coatings exhibited well-sintered and relatively homogeneous structure (Fig. 3) with only negligible oxidation levels $(<0.24 \mathrm{wt} \%$ in all coatings). As the oxide content was found at particle rims only (via extended duration EDX mapping), it could be safely assumed that it was present in the original feedstock already and was incorporated into the coating during the spraying. As shown in Table 1, minimal porosity content only was detected in the coatings (ranging from $0.3-1.1 \%$, decreasing towards interface) and the microhardness differed from $50 \mathrm{HV} 1$ (Al) to $222 \mathrm{HV} 1$ (Ti). The mass densities of the coatings as determined by the Archimedes method are further shown in Table 1.

In Fig. 4, SEM micrographs of the sprayed materials in the angle selective backscatter (AsB) mode are shown. These micrographs were recorded in channeling contrast mode and reveal a finer structure of misoriented subgrains inside of the individual sprayed particles, resulting probably from the impact-induced plastic deformation. This effect was most apparent for the $\mathrm{Ni}$ coating, where also the bimodal character of this feature was clearly seen: while along the particle boundaries the dimensions of the subgrains were of the order of tens of nanometers, in the middle of the particles these subgrains were of the order of micrometers. Similar effect was also observed in the $\mathrm{Al}$ and $\mathrm{Cu}$ coatings. In the $\mathrm{Ti}$ coating, instead, fine subgrain structure was seen all over the particles, forming some kind of anisotropic pattern, probably resulting from the plastic anisotropy of the hep titanium.

To detect any prospective texture orientation in the materials, the measurements were further supported by EBSD investigations of the coatings polished cross-section [28]. In accordance with the results obtained via RUS (section 3.2), the EBSD polar-orientation maps suggested that the studied cold sprayed coatings did not exhibit any significant crystallographic texture and the orientation of the grains and subgrains within the structure is distributed randomly. A typical example of the pole and inversed pole maps is provided in Fig. 5 for Ni coating. 


\subsection{RUS results}

More than 20 resonant modes were detected and identified in the measured frequency range for each sample. However, the resonant spectra for the individual samples differed significantly in the widths of the resonant peaks, i.e. in the vibration damping by internal friction. In Fig. 6, these differences are shown on selected parts of the spectrum and quantified by the internal friction parameters $Q^{-1}$ (see e.g. [24]), which were calculated from ten most dominant peaks in each spectrum by fitting of these peaks by Lorenzian masks. The $Q^{-1}$ values for the $\mathrm{Cu}$ and the $\mathrm{Ni}$ samples differ by nearly two orders of magnitude; the internal friction parameters for the $\mathrm{Al}$ and $\mathrm{Ti}$ samples lie between these two extremes.

Nevertheless, for all materials the internal friction was sufficiently low and the number of identifiable peaks sufficiently high for the determination of the elastic constants. For the calculation of these constants, the combined iterative inverse procedure described in detail in [22] was used; this procedure uses the RUS spectra and the pulse-echo results as the input data and finds such set of elastic constants that the resonant frequencies and the

$v_{\text {IP }}$ and $v_{\text {OOP }}$ velocities calculated for this set fit the input data in the least squares sense. The results of this procedure are listed in Table 1, whereto the respective experimental errors were calculated via the sensitivity analysis procedure described also in [22].

As shown in Table 1, the Young's moduli of all materials in the OOP direction (which are, in general, considered as softer than those in the IP direction) were higher than $70 \%$ of the moduli of the respective bulk materials. Especially for the $\mathrm{Cu}$ sample, the CS material was by only approximately $10 \%$ elastically softer than bulk polycrystalline copper. This indicated very high compactness of the CS coating and good interlocking between the individual grains. The ability of the CS coatings to exhibit as high elastic moduli as $90 \%$ of the bulk value were reported already by Sundararajan et al. [29]. However, in their study such values were only reported after additional heat treatment of the coatings. In the as-sprayed state, the coatings in [29] exhibited a significant deterioration of the elastic moduli due to inter-splat boundary cracking. No evidence of such cracking was present in the presented coatings; the difference of the two studies could be attributed 
to the use of low-pressure system in [29] (10-20 MPa, see e.g. [30] for the discussion of the effect of the gas pressure on the CS coatings) and the use of different powder feedstock.

Furthermore, all CS coatings listed in Table 1 exhibited nearly perfect elastic isotropy. The ratios between the OOP and IP Young's moduli $\alpha$ ranged between 0.98 and 1.03, i.e. the differences from $\alpha=1$ were fully comparable to the experimental errors. Although a similarly perfect elastic isotropy was reported for amorphous alumina coatings [31], for crystalline metallic coatings such results are very rare. Importantly, the isotropy was reached for all CS materials, although these materials belong to different crystallographic classes and the corresponding bulk materials differ significantly in a number of mechanical properties. For the copper coating, in particular, the observed anisotropy was even weaker than anisotropy of bulk polycrystalline copper with significant crystallographic texture and strongly anisotropic spatial arrangement of grain boundaries reported in [27].

In Fig. 7, the results obtained for the CS materials are compared with metals and metallic compounds sprayed by several other methods, in particular by high-velocity oxygen fueling (HVOF), water-stabilized plasma spraying (WSP), atmospheric spraying (APS), wire-arc spraying (WAS), flame spraying (FS), and vacuum plasma spraying (VPS). As the sprayed materials typically exhibit strongly nonlinear character (i.e. the amplitude dependence of the elastic moduli [32]), the map in Fig. 7 comprises only the results obtained by ultrasonic methods, in particular by pulse-echo [25], RUS [19, 26] or by their combination [23]; therefore, all these results refer to very small straining amplitudes and high straining rates typical for ultrasound. The CS materials obviously possess a unique combination of high $E_{\mathrm{OOP}} / E_{\text {bulk }}$ ratio and very weak anisotropy. Comparable properties were achieved only for the APS CoNiCrAlY coating by Waki et al. [26] after an extensive heat treatment of the coating; in the as-sprayed condition, however, all reported materials exhibited both lower $E_{\mathrm{OOP}} / E_{\text {bulk }}$ ratios and stronger anisotropy.

The $E_{\mathrm{OOP}} / E_{\mathrm{bulk}}$ ratios given Table 1 indicate that there was some correlation between this ratio and the observed differences in the internal friction shown in Fig. 6. While the $\mathrm{Cu}$ sample exhibited the highest relative Young's modulus and the lowest internal friction 
parameter $Q^{-1}$, the Ni sample, which is elastically the most softened with respect to the bulk material, had the highest value of $Q^{-1}$. As shown in Fig. 8, the same trend was also followed by the $\mathrm{Al}$ and $\mathrm{Ni}$ samples. The increase of internal friction and the simultaneous decrease of the relative Young's modulus cannot be obviously explained by the porosity, although the relative density $\rho / \rho_{\text {bulk }}$ exhibited the same trend; the differences in $\rho / \rho_{\text {bulk }}$ between the individual materials are by approximately one order of magnitude smaller than those in the relative Young's moduli. The discrepancy could be partially explained by the fact that the effect of porosity onto the elastic constants of the sprayed coatings may follow not only from the total volume fraction, but also from shapes and spatial arrangement of the pores (cf. [33]). However, it is plausible that there is an additional source of this simultaneous softening and internal friction increase originating directly from the microstructure of the coatings. As reported by Zou [34] and Zou et al. [35], the aluminum and nickel CS coatings contain some amount of highly misoriented, equiaxed nano-sized grains, probably formed by sub-grain rotation under impacts during the spraying, while no such grains can be found in the CS copper coatings. Consequently, it is plausible that these grains contribute to softening and internal friction of the analyzed coatings by grain boundary sliding (GBS), as GBS at room temperature in nano-grained aluminum, nickel and titanium was reported several times [36, 37, 38, 39].

From another point of view, both the lowest value of the internal friction and the highest value of the relative Young's modulus $E_{\mathrm{OOP}} / E_{\mathrm{bulk}}$ indicate that the copper coating exhibited the best integrity and compactness among the examined materials. This is in a good agreement with the fact that the sprayability of copper is the best among the examined materials. Nevertheless, even for the materials with initially worse sprayability (especially titanium with the hcp structure), the results reported in this paper show that the CS coatings exhibit, among other sprayed materials, superior elastic properties, both in the $E_{\mathrm{OOP}} / E_{\mathrm{bulk}}$ ratio and as far as the resulting elastic anisotropy is concerned. As seen in the map in Fig. 7, all examined CS materials were comparable in this respect, and thus, it can be concluded that such unique properties are not particular to the individual sprayed metals, but follow from the CS technology itself. 


\section{Conclusions}

Four cold sprayed materials (Al, Cu, Ni, Ti) were studied by contact-less laser-based RUS. It was shown that, in the elastic deformation range, the fabricated metallic coatings exhibited nearly perfectly isotropic behavior, making cold spray unique among all other thermal spraying methods. Further to that, the obtained values of Young's moduli of the studied coatings were well comparable to those of the corresponding bulk materials, an additional indication of the outstanding compactness achieved by the CS process.

On the other hand, especially the Ni and Ti CS coatings exhibited an increased level of internal friction. Simultaneously, these coatings were elastically slightly softer than what could be ascribed to the effect of porosity. It is therefore assumed that this behavior can be interpreted as a result of intense plastic deformation of the sprayed material during the CS process, leading to grain refinement and, consequently, to enhanced grain boundary sliding. From this point of view, the elasticity of CS coatings may exhibit features similar to bulk materials processed by severe plastic deformation methods, for which the slight softening of elastic constants and simultaneous increase of internal friction due to grain refinement is also well detectable by RUS measurements [27, 41].

\section{Acknowledgment}

The work of H.S., P.S. and M.L. has been financially supported by the Czech Science Foundation (project No. GA13-13616S). The work of J.C., J.C. and I.D. has been also financially supported by the Czech Science Foundation (project No. GA13-35890S) and has been carried out within NETME Centre Plus (LO1202) project co-funded within the support programme National Sustainability Programme I.

\section{References}

[1] A. Papyrin, V. Kosarev, S. Klinkov, A. Alkhimov, V. Fomin, Cold spray technology, Elsevier, Amsterdam, 2007.

[2] J. Cizek, O. Kovarik, J. Siegl, K.A. Khor, I. Dlouhy, Surf Coat Technol 217 (2013) 23. 
[3] T. Schmidt, H. Assadi, F. Gartner, H. Richter, T. Stoltenhoff, H. Kreye, T. Klassen, J Therm Spray Technol 18 (2009) 794.

[4] R. Tucker (Ed.), ASM Handbook: Thermal spray technology, ASM International, Materials Park, 2013.

[5] J. Cizek, O. Man, P. Roupcova, K. Loke, I. Dlouhy, Surf Coat Technol 268 (2015) 85.

[6] J. Cizek, M. Matejkova, I. Dlouhy, F. Siska, C.M. Kay, J. Karthikeyan, S. Kuroda, O. Kovarik, J. Siegl, K. Loke, K.A. Khor, J Therm Spray Technol 24 (2015) 758.

[7] P. Fauchais, J.V.R. Heberlein, M.I. Boulos, Thermal Spray Fundamentals: From Powder to Part, Springer US, New York. 2014.

[8] R. Musalek, O. Kovarik, J. Matejicek, Surf Coat Technol 205 (2010) 1807.

[9] J. Nohava, R. Musalek, J. Matejicek, M. Vilemova, Surf Coat Technol 240 (2014) 243.

[10] J. Cizek, I. Dlouhy, F. Siska, K.A. Khor, J Therm Spray Technol 23 (2014) 1339.

[11] R. Morgan, P. Fox, J. Pattison, C. Sutcliffe, W. O’Neill, Mater Lett 58 (2004) 1317.

[12] H. Assadi, F. Gartner, T. Stoltenhoff, H. Kreye, Acta Mater 51 (2003) 4379.

[13] R. Ahmed, N. Faisal, S. Knupfer, A. Paradowska, M. Fitzpatrick, K.A. Khor, J. Cizek, Mater Sci Forum 652 (2010) 309.

[14] R.C. McCune, W.T. Donlon, O.O. Popoola, E.L.Cartwright, J Therm Spray Technol $9(2000) 73$.

[15] V.K. Champagne, The cold spray materials deposition process: Fundamentals and applications, Woodhead publishing, Abington, 2007.

[16] T. Stoltenhoff, C. Borchers, F. Gartner, H. Kreye, Surf Coat Technol 200 (2006) 4947.

[17] P. Fauchais, J. Phys D: Appl Phys 37 (2004) R86. 
[18] V.V. Sobolev, Mater Lett 36 (1998) 123.

[19] Y. Tan, A. Shyam, W.B. Choi, E. Lara-Curzio, S. Sampath, Acta Mater 58 (2010) 5305.

[20] A. Migliori, J.L. Sarrao, W.M. Visscher, T.M. Bell, L. Ming., Z. Fisk. R.G. Leisure, J Phys B: Condens Matter 183 (1993) 1.

[21] R.G. Leisure, F.A. Willis, J Phys: Condens Matter 28 (1997) 6001.

[22] P. Sedlak, H. Seiner, J. Zidek, M. Janovska, M. Landa, Exp Mech 54 (2014) 1073.

[23] P. Sedmak, H. Seiner, P. Sedlak, M. Landa, R. Musalek, J. Matejicek, Surf Coatings Technol 232 (2013) 747.

[24] A.S. Nowick, B.S. Berry, Anelastic relaxation in crystalline solids. Academic Press, New York, 1972.

[25] N. Margadant, J. Neuenschwander, S. Stauss, H. Kaps, A. Kulkarni, J. Matejicek, G. Rossler, Surf Coat Technol 200 (2006) 2805.

[26] H. Waki, S. Kubo, H. Ogi, A. Kobayashi, T Jpn Soc Mech Eng A 762 (2010) 151.

[27] H. Seiner, L. Bodnarova, P. Sedlak, M. Janecek, O. Srba, R. Kral, M. Landa, Acta Mater 58 (2010) 235.

[28] J. Cizek, H. Seiner, R. Huang, M. Landa, I. Dlouhy. Proceedings of the ITSC 2015, ASM International, Long Beach, USA, 353.

[29] G. Sundararajan, N.M. Chavan, and S. Kumar, J Therm Spray Technol 22 (2013) 1349 .

[30] H. Lee, H. Shin, S. Lee, K. Ko, Mater Lett 62 (2008) 1579.

[31] H.J. Kim, Y.G. Kweon, Thin Solid Films 342 (1999) 201.

[32] F. Kroupa, J Therm Spray Technol 16 (2007) 84.

[33] D. Schneider, T. Schwarz, Thin Solid Films 224(1993) 177. 
[34] Y. Zou, Ph.D. thesis, McGill University, Montreal, 2010.

[35] Y. Zou, W. Qin, E. Irissou, J. G. Legoux, S. Yue, J. A. Szpunar, Scripta Mater 61 (2009) 899.

[36] S. X. McFadden, R. S. Mishra, R. Z. Valiev, A. P. Zhilyaev, A. K. Mukherjee, Nature 396 (1998) 684.

[37] M.A. Meyers, A. Mishra, D.J. Benson, Progress Mater Sci 51 (2006) 427.

[38] N.Q. Chinh, P. Szommer, Z. Horita, T.G. Langdon, Adv Matter 18 (2006) 34.

[39] R.Z. Valiev, A.V. Sergueeva, A.K. Mukherjee, Scripta Mater 49 (2003) 66.

[40] A. Briggs, Acoustic Microscopy, Claredon Press, Oxford, 1992.

[41] M. Koller, P. Sedlak, H. Seiner, M. Sevcik, M. Landa, J. Straska, M. Janecek, J Mater Sci 50 (2015) 808. 
Table 1: Elastic constants $c_{i j}$ and the Young's moduli $\left(E_{\mathrm{IP}}, E_{\mathrm{OOP}}\right)$ of the analyzed CS materials; the anisotropy ratio $\alpha$ characterizes the difference between IP and OOP properties. For comparison, the values of the Young's moduli for bulk materials are given [40]. The constant $c_{66}$ was calculated as $\left(c_{11}-c_{12}\right) / 2$. Further included is density, porosity, and microhardness of the coatings.

\begin{tabular}{lrrrr}
\hline \hline & $\mathrm{Al}$ & $\mathrm{Cu}$ & $\mathrm{Ni}$ & $\mathrm{Ti}$ \\
\hline$c_{11}[\mathrm{GPa}]$ & $86.2 \pm 0.4$ & $183.3 \pm 1.4$ & $188.8 \pm 1.6$ & $116.1 \pm 0.9$ \\
$c_{12}[\mathrm{GPa}]$ & $40.1 \pm 0.4$ & $95.5 \pm 1.5$ & $76.7 \pm 2.4$ & $48.9 \pm 1.1$ \\
$c_{13}[\mathrm{GPa}]$ & $38.6 \pm 0.4$ & $94.6 \pm 1.1$ & $75.1 \pm 2.5$ & $43.6 \pm 1.3$ \\
$c_{33}[\mathrm{GPa}]$ & $83.3 \pm 0.5$ & $179.7 \pm 1.3$ & $185.1 \pm 1.6$ & $114.7 \pm 0.8$ \\
$c_{44}[\mathrm{GPa}]$ & $23.3 \pm 0.1$ & $42.5 \pm 0.1$ & $54.6 \pm 1.0$ & $34.4 \pm 0.3$ \\
$c_{66}[\mathrm{GPa}]$ & $23.0 \pm 0.1$ & $43.9 \pm 0.2$ & $56.1 \pm 2.0$ & $33.6 \pm 0.2$ \\
& & & & \\
$E_{\mathrm{IP}}[\mathrm{GPa}]$ & $61.1 \pm 0.6$ & $117.9 \pm 2.0$ & $144.9 \pm 2.3$ & $89.1 \pm 1.2$ \\
$E_{\text {OOP }}[\mathrm{GPa}]$ & $59.7 \pm 0.7$ & $115.5 \pm 2.1$ & $142.7 \pm 3.0$ & $91.4 \pm 1.5$ \\
$\alpha=E_{\mathrm{OOP}} / E_{\mathrm{IP}}$ & $0.98 \pm 0.01$ & $0.98 \pm 0.02$ & $0.98 \pm 0.02$ & $1.03 \pm 0.02$ \\
& & & & \\
$E_{\text {bulk }}[\mathrm{GPa}]$ & 70 & 130 & 201 & 121 \\
$E_{\text {OOP }} / E_{\text {bulk }}$ & 0.85 & 0.89 & 0.72 & 0.76 \\
& & & & \\
Density $\left[\mathrm{g} \cdot \mathrm{cm}{ }^{-3}\right]$ & 2.59 & 8.75 & 8.36 & 4.28 \\
Porosity $[\%]$ & 0.8 & 1.1 & 0.4 & 0.3 \\
Microhardness $[\mathrm{HV} 1]$ & 50 & 190 & 220 & 222 \\
\hline \hline
\end{tabular}



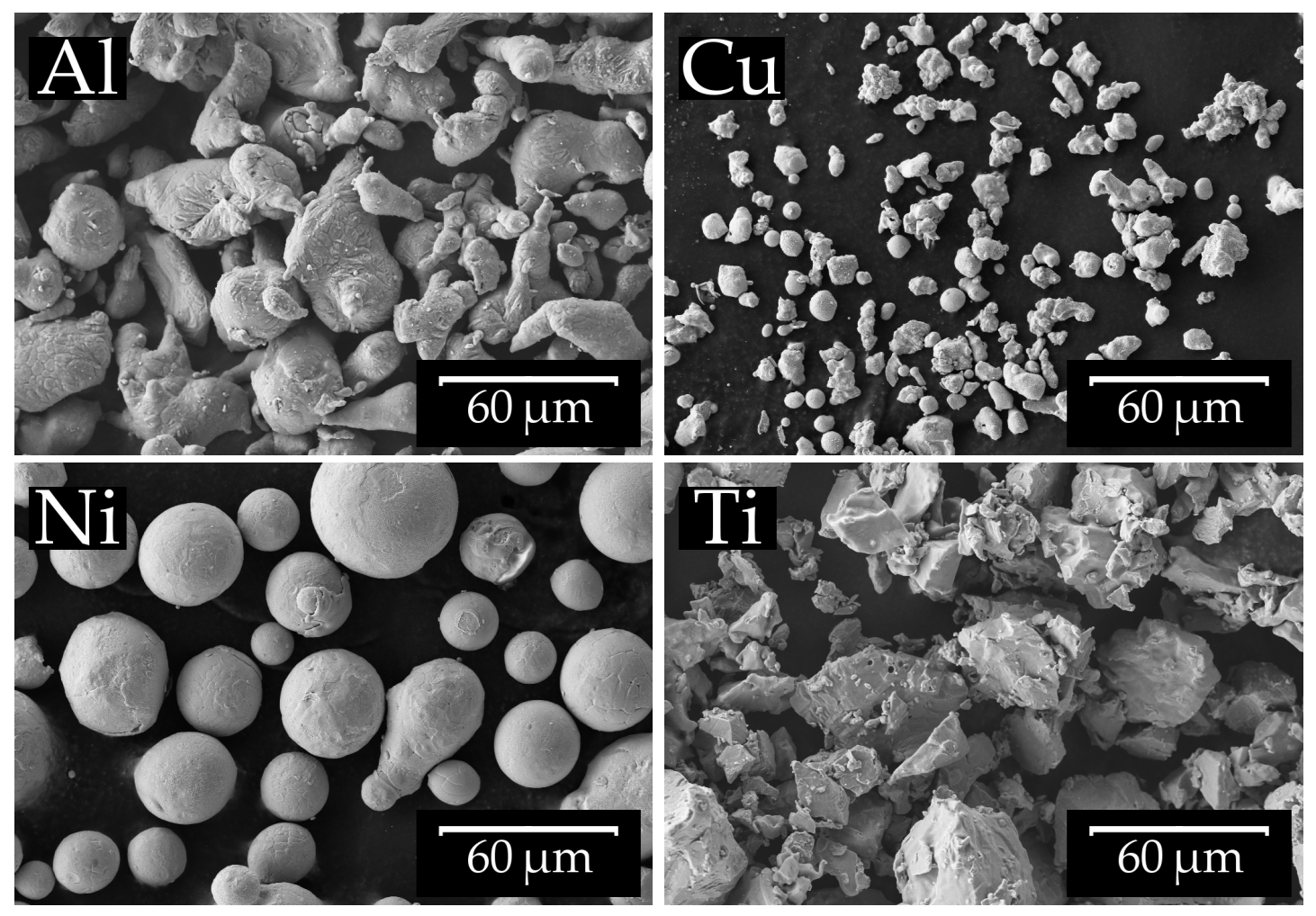

Figure 1: Morphology of the $\mathrm{Al}, \mathrm{Cu}, \mathrm{Ni}$, and $\mathrm{Ti}$ powders used for $\mathrm{CS}$ coatings fabrication 


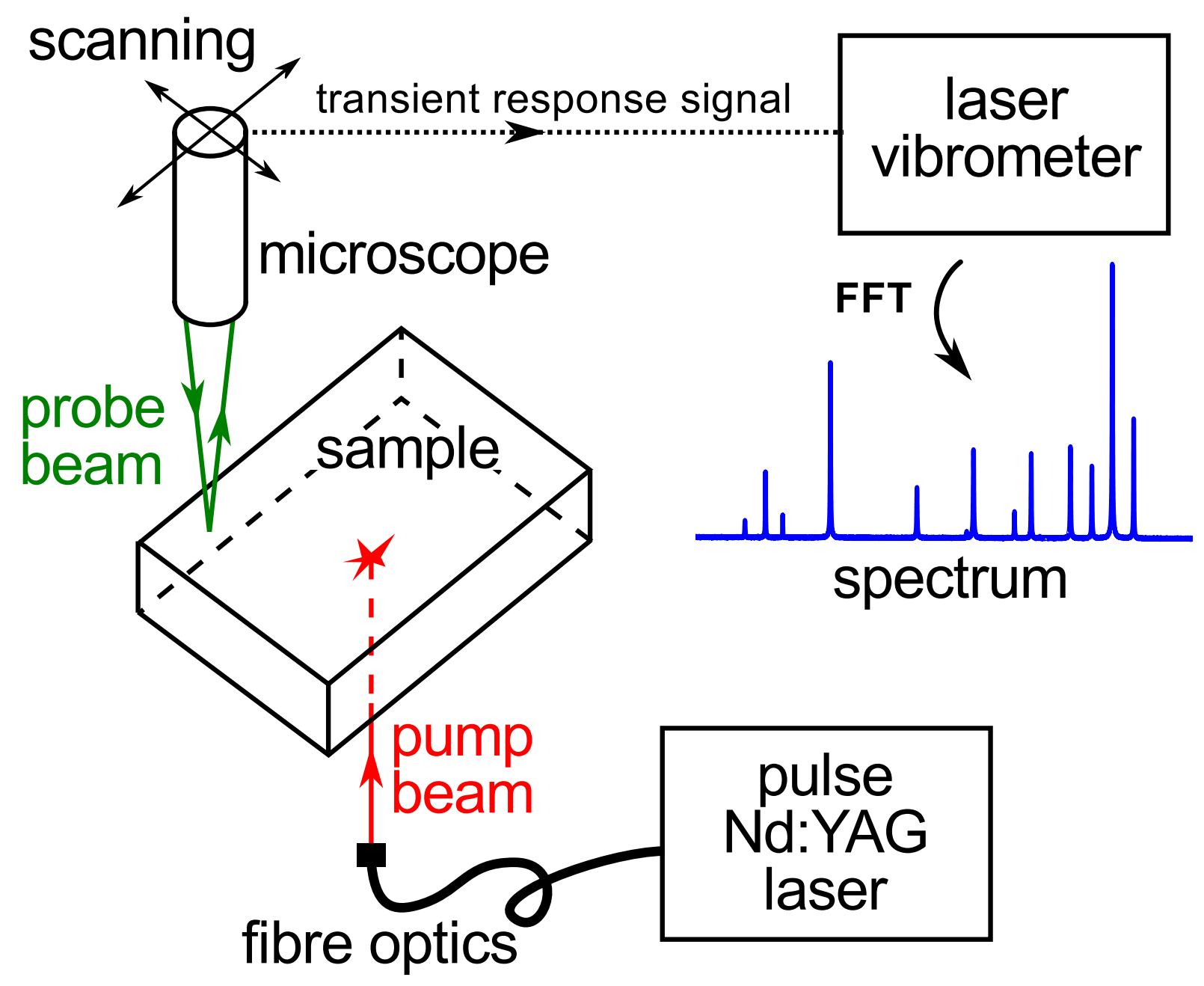

Figure 2: Schematics of the RUS setup 


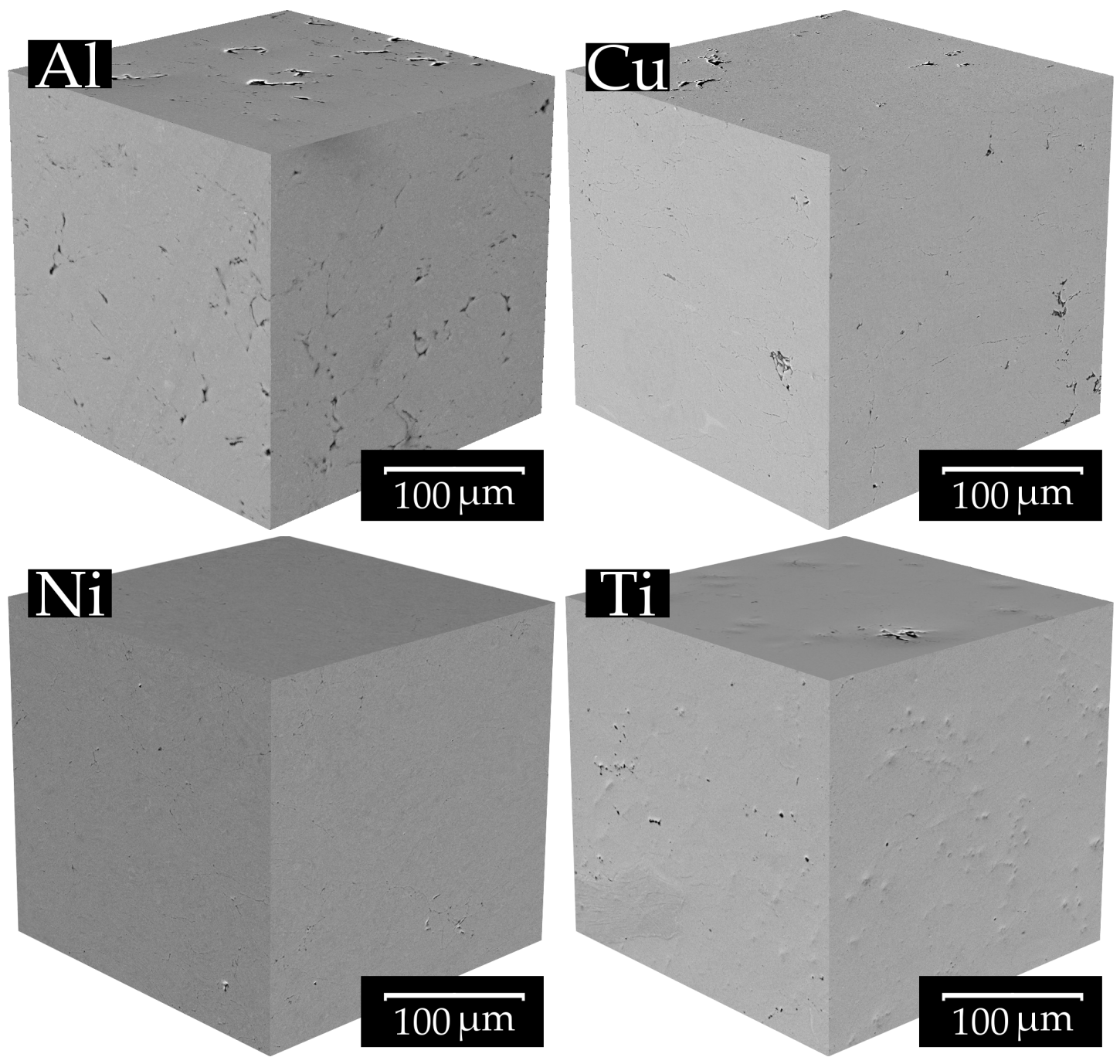

Figure 3: Compact structure of the $\mathrm{Al}, \mathrm{Cu}, \mathrm{Ni}$, and $\mathrm{Ti}$ coatings fabricated via high-pressure cold spray 

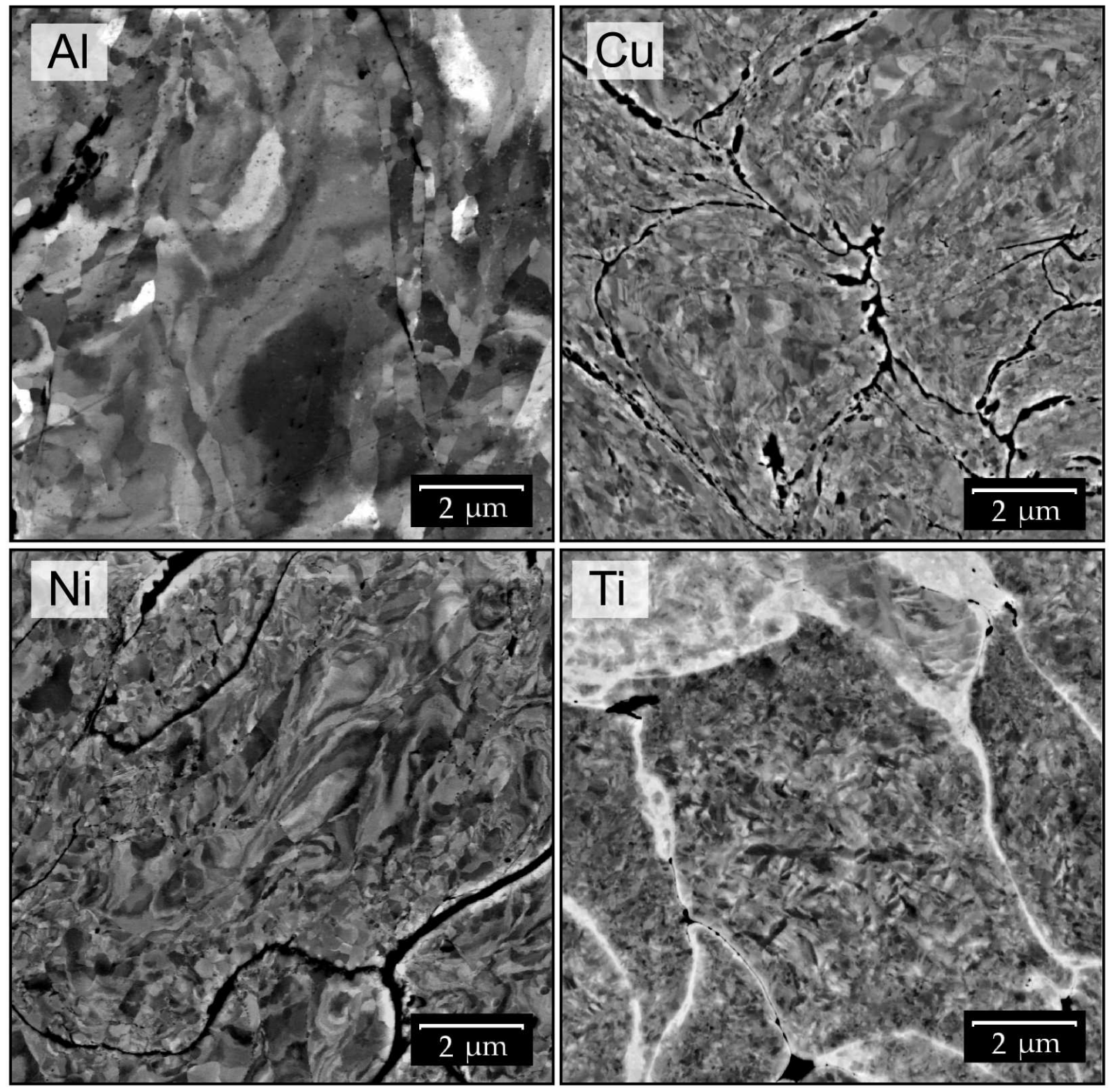

Figure 4: Morphology of the cold spray deposited Al, Cu, Ni, and Ti coatings (Zeiss FE-SEM, AsB mode, channeling contrast, $10 \mathrm{kV}, \mathrm{WD}=3.5 \mathrm{~mm}$ ). Individual particles could be partially distinguished in the structure. Within the particles, the gray-scale contrast corresponds to misorientation of subgrains formed upon impact. In all micrographs, the vertical direction corresponds to the spraying direction. 

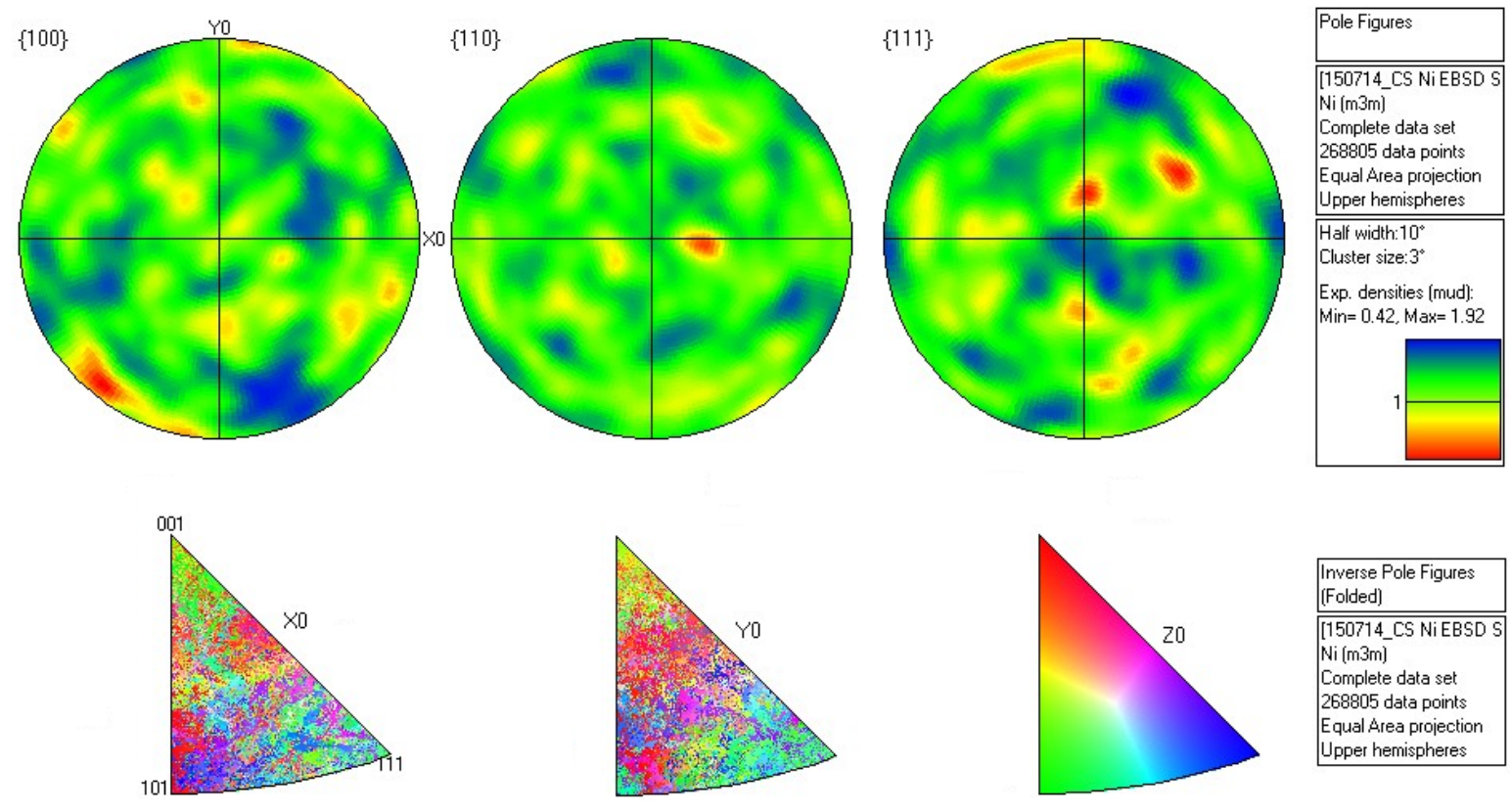

\begin{tabular}{|l|}
\hline $\begin{array}{l}\text { Inverse Pole Figures } \\
\text { (Folded) }\end{array}$ \\
\hline [150714_CS Ni EBSD S \\
Ni (m3m) \\
Complete data set \\
268805 data points \\
Equal Area projection \\
Upper hemispheres \\
\hline
\end{tabular}

Figure 5: EBSD pole and inverse pole figures of Ni cold spray coating. No preferred orientation texture was detected in the coatings. (Color online.) 

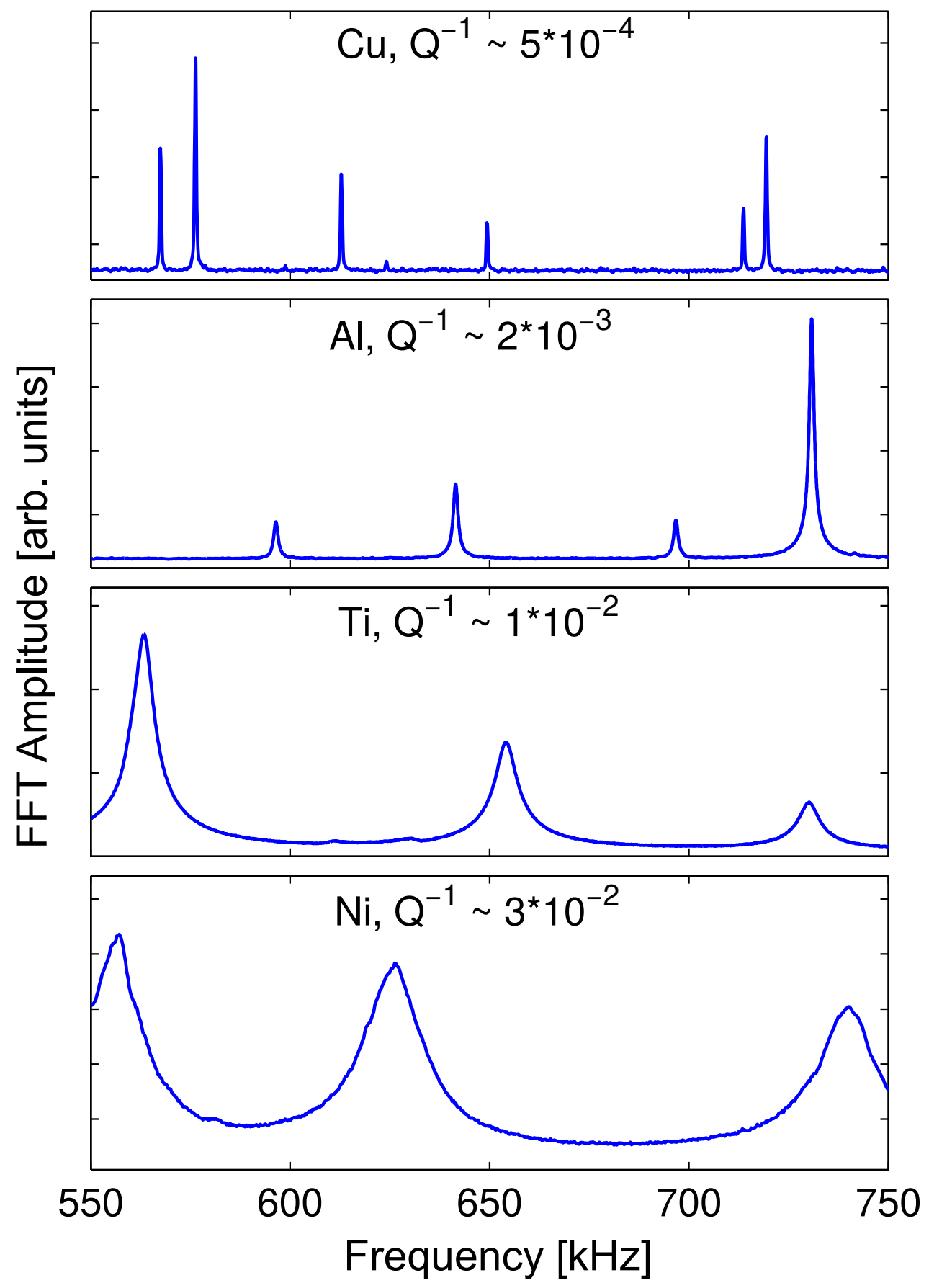

Figure 6: Selected parts of the RUS spectra for the $\mathrm{Cu}, \mathrm{Al}$, Ti and Ni CS samples illustrating the differences in the internal friction parameters $Q^{-1}$. (Color online.) 


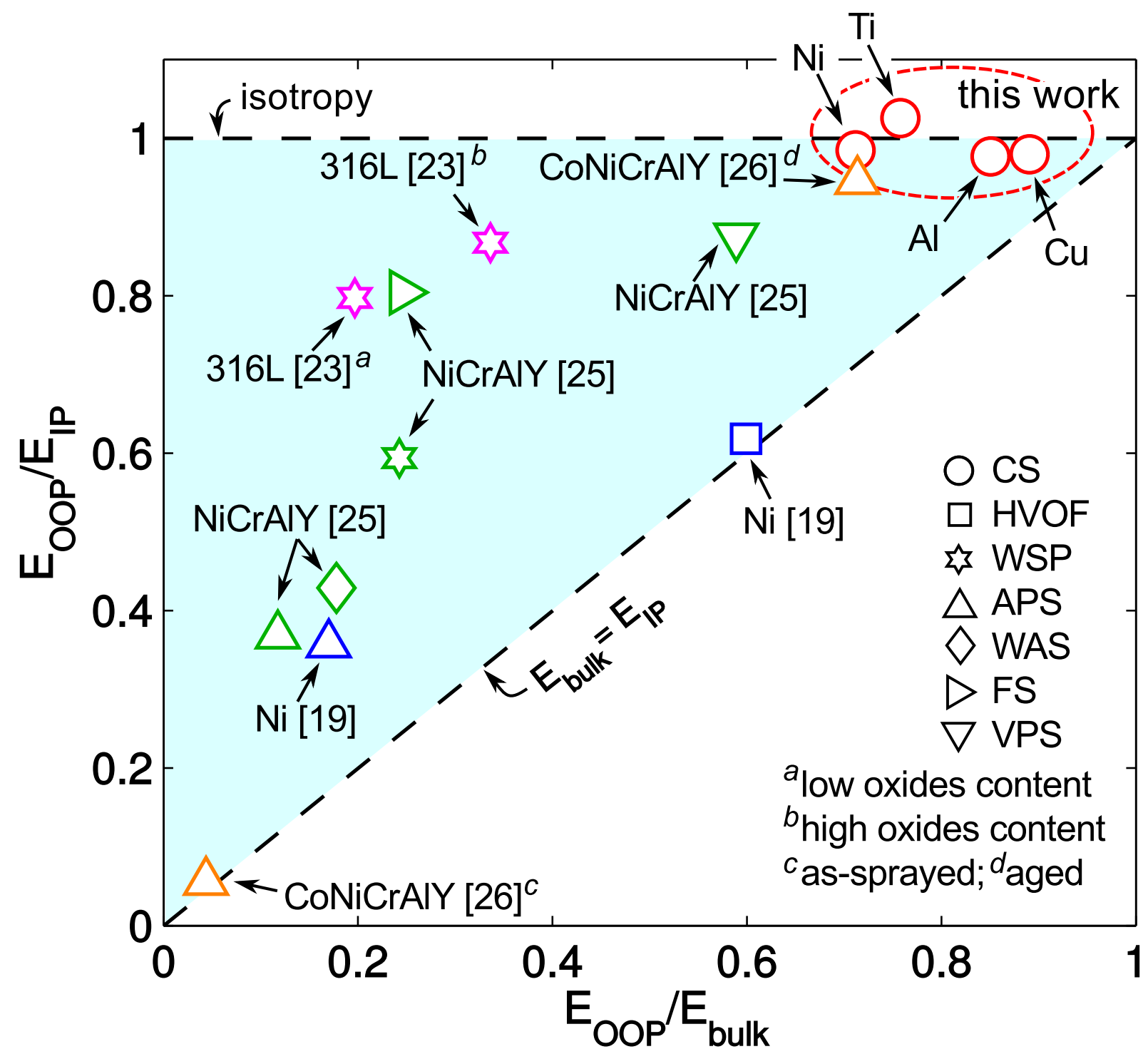

Figure 7: A comparison of the elastic properties of the CS materials with other sprayed metals and metallic compounds; the horizontal axis of the map represents the relative elastic weakening of the sprayed material with respect to the bulk material $E_{\mathrm{OOP}} / E_{b u l k}$, the vertical axis gives the anisotropy of the coating $E_{\mathrm{OOP}} / E_{\mathrm{IP}}$. The shaded triangle is the area of validity of the $E_{\mathrm{OOP}} \leq E_{\mathrm{IP}} \leq E_{\mathrm{bulk}}$ relation followed approximately by all plotted materials; the different markers refer to different spraying methods (see the text for the acronyms), the numbers in square brackets refer to the list of references. (Color online.) 


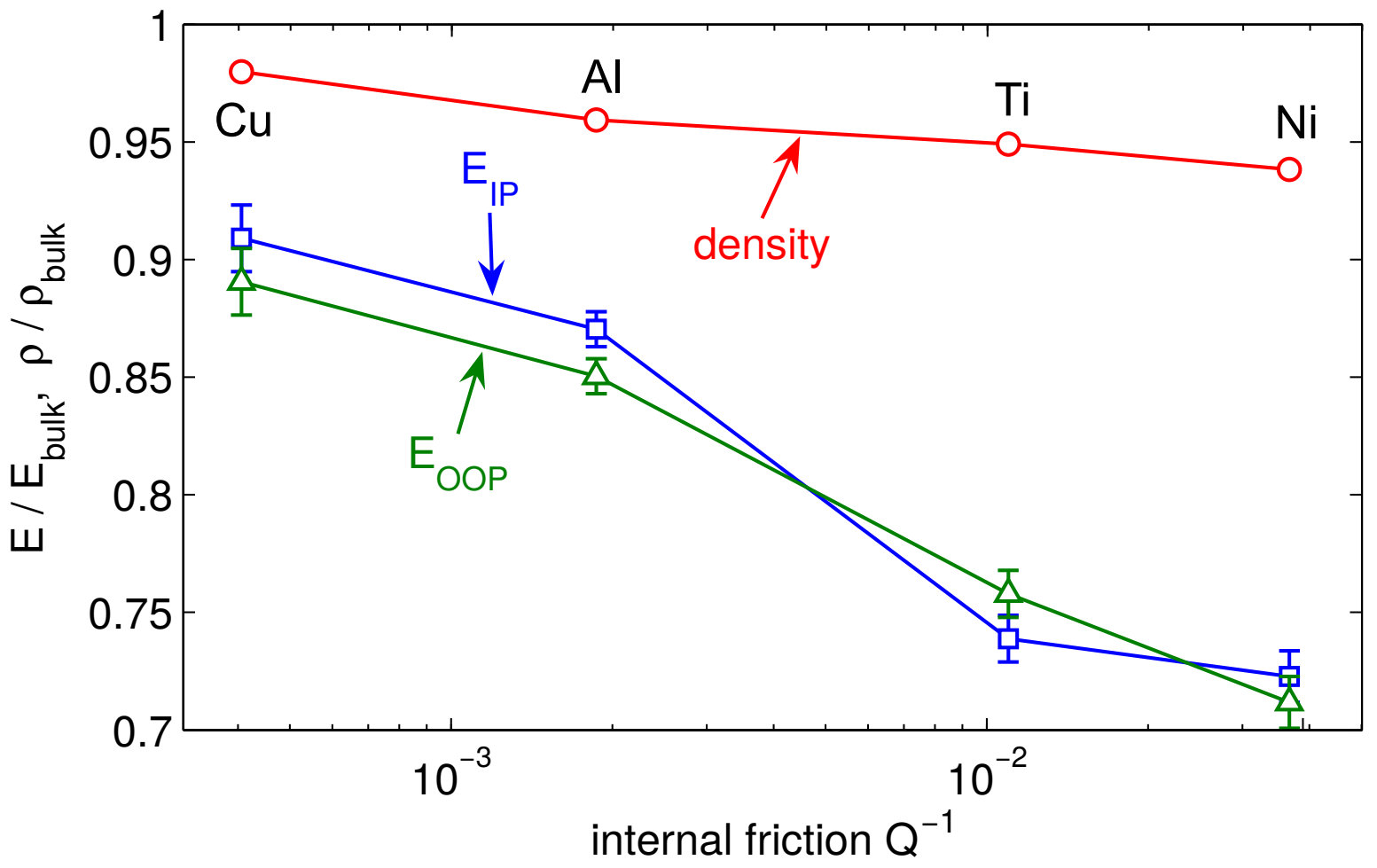

Figure 8: Correlation between the internal friction parameter $Q^{-1}$ and the relative density $\left(\rho / \rho_{\text {bulk }}\right)$ and Young's moduli ( $E_{\mathrm{IP}} / E_{\mathrm{bulk}}$ and $\left.E_{\mathrm{OOP}} / E_{\mathrm{bulk}}\right)$. (Color online.) 